\title{
Facade Ventilation Design of New Building Photovoltaic Curtain Wall in Cold City
}

\author{
Xin Zheng ${ }^{1}$, Wei Li ${ }^{2}$ \\ ${ }^{1}$ School of Art Design, Jilin Jianzhu University, Changchun, 130118, China \\ ${ }^{2}$ School of Architecture and City Plan, Jilin Jianzhu University, Changchun, 130118, China \\ xin_zheng2014@yeah.net
}

Keywords: Photovoltaic curtain wall, Ventilation performance, Orifice plate flow, Cold City, Data acquisition, PLC system.

\begin{abstract}
In order to study the facade ventilation performance of new building photovoltaic curtain wall, we select a set of photovoltaic curtain wall as the research object in cold city to carry on the ventilation performance test, and this paper proposes a new method of orifice plate flow test photovoltaic curtain wall ventilation performance. The test system uses PLC as the data acquisition and upload system, the different height of photovoltaic curtain wall has been the layout of measuring points, and then using orifice plate flow meter and thermometer respectively test the air flow and the indoor temperature measuring point, finally we found by testing that the following arrangement inclined photovoltaic components of building outside window can not only ensure the building with larger photovoltaic panels installation area, but also will not affect the building normal opening window, which is a new photovoltaic curtain wall installing method, and can be promoted the use in cold city.
\end{abstract}

\section{Introduction}

In order to study the facade ventilation performance of new building photovoltaic curtain wall, we select a set of photovoltaic curtain wall as the research object in cold city to carry on the ventilation performance test, and this paper proposes a new method of orifice plate flow test photovoltaic curtain wall ventilation performance [1-3]. The test system uses PLC as the data acquisition and upload system, the different height of photovoltaic curtain wall has been the layout of measuring points, and then using orifice plate flow meter and thermometer respectively test the air flow and the indoor temperature measuring point, finally we found by testing that the following arrangement inclined photovoltaic components of building outside window can not only ensure the building with larger photovoltaic panels installation area, but also will not affect the building normal opening window, which is a new photovoltaic curtain wall installing method and can promote the use in cold waterfront city.

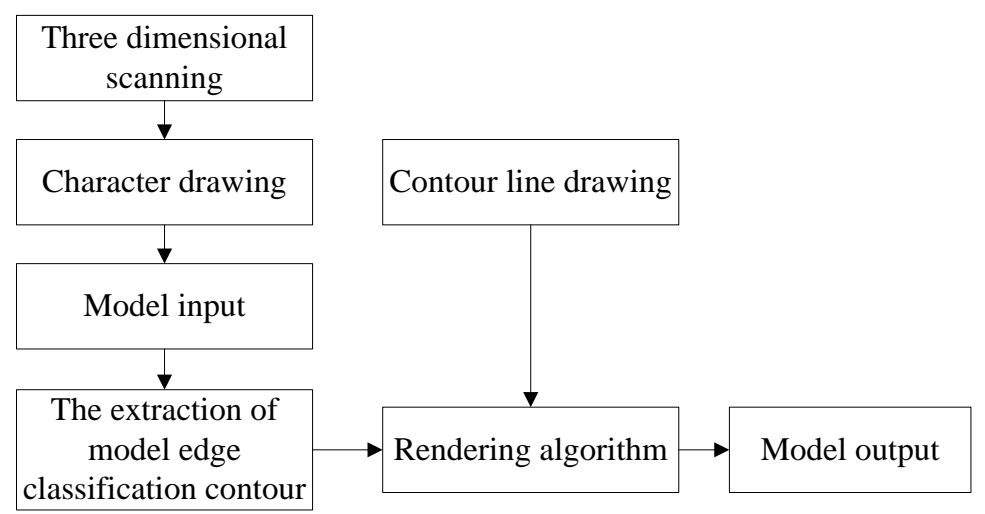

Fig.1: Schematic diagram of character image extraction implementation framework

Figure 1 shows the validation process schematic diagram of photovoltaic glass energy saving environmental protection performance designed in this paper, it is mainly ordinary glass, photovoltaic glass and tilt photovoltaic glass as the research object, to carry on the study of the ventilation performance and improving indoor temperature performance [4,5]. Finally, we carry out 
summary for the test parameters of the environmental performance, and the use of database software creates database system, which can provide reference data for the design of photovoltaic glass curtain wall.

\section{Design of Photovoltaic Curtain Wall Ventilation Flow Test Modeling and Algorithm}

In order to test all kinds of curtain wall ventilation speed, this paper designs a new orifice meter method. This method goes through the orifice plate to increasing the flow velocity, after the airflow velocity is increased, the pressure difference before and after orifice plate will also be increased, so we can go through measuring the differential pressure to measure the size of air flow, so as to test the ventilation speed [6-8]. The method is based on the two equations, and the two equations are the continuity equation and the energy conservation law, the basic design schematic diagram is shown in Figure 2.

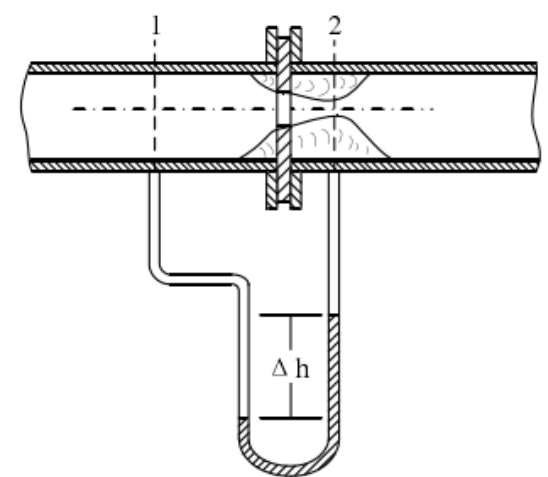

Fig.2: Photovoltaic curtain wall orifice meter section

Figure 2 shows the section of photovoltaic curtain wall orifice plate flow meter, it can be seen from the chart that when the gas flowing goes through the orifice plates, its beam section will be the size of shrinkage hole section, after it goes through hole, it still continues to shrink, and then it gradually expands, in which the energy balance equation of 1 and 2 two position sections is:

$$
Z_{1}+\frac{P_{1}}{\lambda}+\frac{a_{1} v_{1}}{2 g}=Z_{2}+\frac{P_{2}}{\lambda}+\frac{a_{2} v_{2}}{2 g}+h_{w} .
$$

Wherein, $Z_{1}$ and $Z_{2}$ show the position height of 1 and 2 section; $P_{1}$ and $P_{2}$ represent the pressure of 1 and 2 section; $v_{1}$ and $v_{2}$ represent the flow rate of 1 and 2 section; $a_{1}$ and $a_{2}$ represent the function correction coefficient of 1 and 2 section; $h_{w}$ shows the friction loss of 1 and 2 section; $\rho$ shows gas density; $g$ shows the gravity acceleration, then the air flow can be expressed as:

$$
Q=k A_{0} \sqrt{2 g} \sqrt{\frac{P_{1}-P_{2}}{\lambda}} .
$$

Among them, $k$ shows orifice plate flow meter's calibration coefficient; $A_{0}$ represents the opening area of orifice, and then the standard formula for air flow calculation is

$$
Q_{V n}=A_{V n} C E d^{2} F_{G} \varepsilon F_{Z} F_{T} \sqrt{P_{1} \Delta P} \text {. }
$$

Among them, $Q_{V n}$ shows the volume flow of air under the standard conditions; $A_{v n}$ expresses the volume flow of using certain measuring unit; $C$ shows the outflow coefficient; $E$ indicates the gradual coefficient of velocity; $d$ represents the diameter of opening orifice; $F_{G}$ represents relative density coefficient; $\varepsilon$ shows expandable coefficient; $F_{Z}$ shows super compressibility coefficient; $F_{T}$ shows flow temperature coefficient, $P_{1}$ represents pressure hole absolute air static from orifice plate upstream. In order to realize the ventilation flow monitoring of photovoltaic curtain wall, testing system is controlled by the way of programming, in which the main PLC algorithm are as follows [9-11]:

LDN M0. 0 
R SM87. 7, 1

RCV VB800, 0

XMT VB700, 0

LD M0. 2

R SM87. 7, 1

RCV VB800，0

XMT VB700, 0

LD SM0. 0

RCV VB800, 0

LD SM0.1

LD SM0.0

CALL MBUS_SLAVE:SBR2, M0.2, MB2

\section{Study of Cold Building Photovoltaic Curtain Wall Ventilation and Low Carbon Performance}

In order to verify the effectiveness and reliability of orifice plate flow air measurement model designed in second section, this paper uses photovoltaic curtain wall ventilation energy saving experiment methods to verify the algorithm, in which the data is collected by through the implementation of PLC system, and PLC can use the ARM processor on the system performance to carry on topology, as shown in Figure 3.

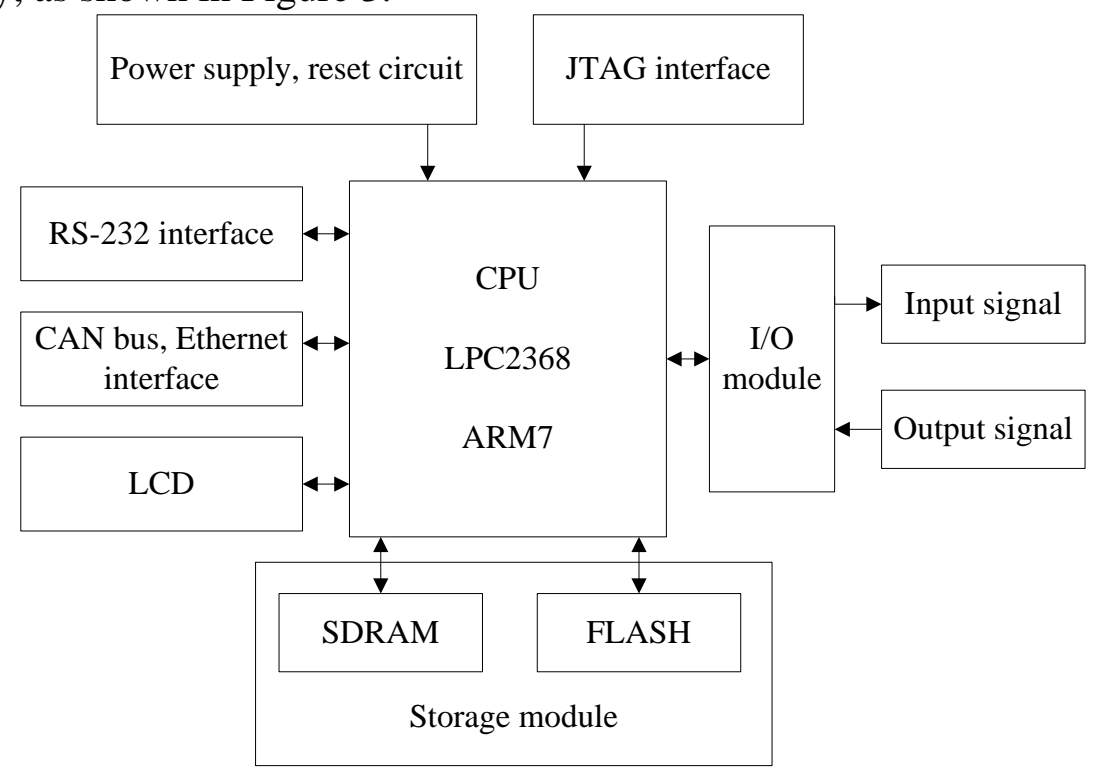

Fig.3: The topology schematic of PV curtain wall PLC data acquisition system

As shown in Figure 3, it represents the topology schematic of PV curtain wall PLC data acquisition system. The topological structure mainly includes power and reset circuit, and also including different kinds of interface, such as CAN interface, RS-485 interface, I/O module and so on $[12,13]$. The various ventilation data and saving energy data acquisition of photovoltaic curtain wall can be achieved by topology, the experiment uses photovoltaic curtain wall form as shown in Figure 4. 


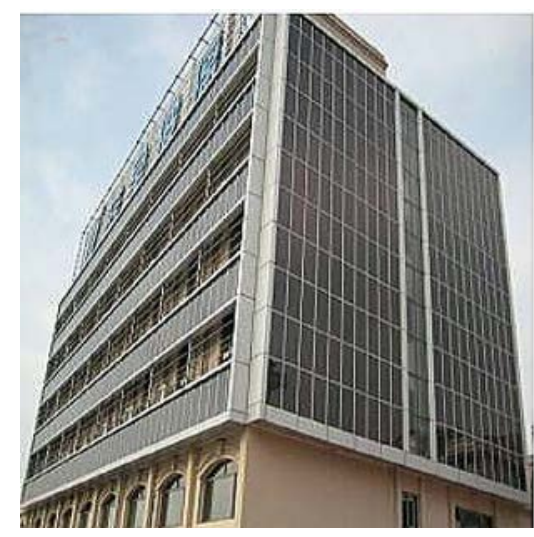

Fig.4: Schematic diagram of photovoltaic curtain wall

Figure 4 shows the schematic diagram of photovoltaic curtain wall, the main energy transmission way carries out solar energy collected by photovoltaic curtain wall, and then photovoltaic curtain wall and indoor wall surface carry out heat transfer, finally the interior walls go through the heat exchange to achieve room temperature conditions, so the effect of ventilation has larger on the performance of building [14-16]. In order to research the ventilation performance of photovoltaic curtain wall, the data is collected and processed by using PLC system, in which the acquisition system analyzer is used as shown in Figure 5.

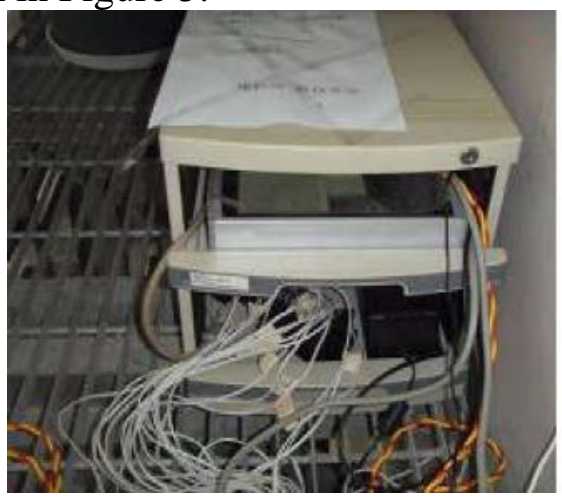

Fig.5: Schematic diagram of data acquisition terminal

Figure 5 shows the schematic diagram of the wind speed acquisition terminal, and we use orifice plate flow meter as the main components of ventilation test in the system, the interval of sampling time is 10 minutes, and then the data is transmitted to the host computer through PLC, finally the data is stored in the hard disk.

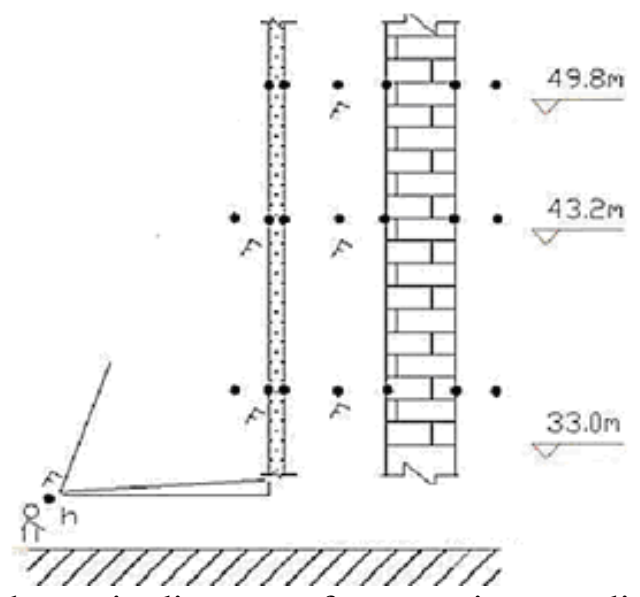

Fig.6: Schematic diagram of test equipment distribution

Figure 6 shows the distribution schematic diagram of testing instrument in architecture, we respectively arrange testing instrument in a different building height, wherein the height mainly include 4.9.m, 49.2m and 33.0m three position [17]. Through the test, the ventilation results are shown in Table 1. 
Table 1: Ventilation test results

\begin{tabular}{lllll}
\hline $\begin{array}{l}\text { Test } \\
\text { number }\end{array}$ & $\begin{array}{l}\text { Ordinary } \\
\text { window } \\
\text { (Wind speed } / \mathrm{m} / \mathrm{s} \text { ) }\end{array}$ & $\begin{array}{l}\text { glass } \\
\text { (Window } \\
\text { (Wind speed } / \mathrm{m} / \mathrm{s} \text { ) }\end{array}$ & $\begin{array}{l}\text { glass } \\
\text { (Windting } \\
\text { (Wind speed } / \mathrm{m} / \mathrm{s} \text { ) }\end{array}$ & glass \\
\hline 1 & 0.22 & 0.35 & 0.56 & \\
2 & 0.19 & 0.32 & 0.59 & \\
3 & 0.25 & 0.29 & 0.55 & \\
4 & 0.21 & 0.27 & 0.52 & \\
\hline
\end{tabular}

Table 1 shows the final test results of ventilation performance, it can be seen from the table that the ventilation performance of photovoltaic glass window is better than ordinary glass, and the ventilation performance of tilt photovoltaic glass curtain wall is best [18]. For the energy saving environmental protection of test different glass curtain wall, the results are obtained as shown in Figure 7.

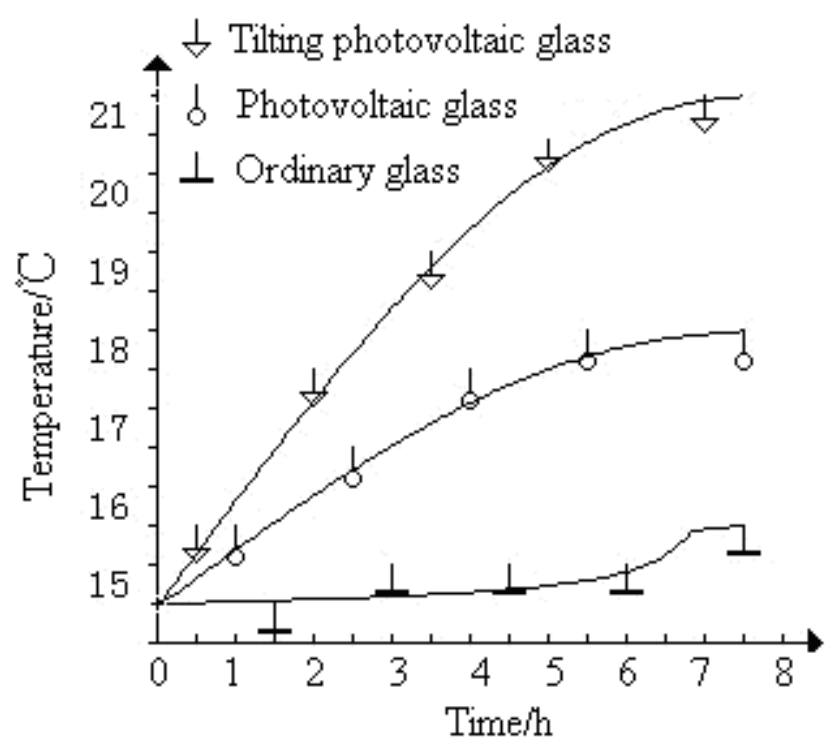

Fig.7: Energy-saving test results

Figure 7 shows the energy saving and environmental protection performance test of inclined type photovoltaic glass window, it can be seen from the chart that using the inclined type photovoltaic glass as the curtain wall can improve indoor temperature effectively, thus it can be seen that the inclined glass windows has not only good ventilation effect, but also has good low carbon and environmental protection function, which can be promoted the use in cold city.

\section{Summary}

(1) According to mass conservation and continuity equation theory, this paper proposes a new ventilation test system of photovoltaic curtain wall, the system uses the orifice plate flow meter as a terminal component test; using the PLC programming control system carries out the data collection, which is uploaded to the PC for data preservation.

(2) The ventilation of new photovoltaic curtain wall and energy-saving environmental protection performance are measured in cold city, we found that using tilt photovoltaic component installation method not only can improve the ventilation performance, but also can improve the performance of building energy saving environmental protection, which provide a new scheme for the building energy conservation environmental protection of cold city.

\section{References}

[1] R. Zhang, G.Q. Hao, X.T. Yu. Analysis of the ventilation cavity design of photovoltaic building roof. Building science, 2013(4): 112-113. 
[2] L. Wang, Y.Q. Pan, Z.Z. Huang. Analysis of affecting factors of building window exterior natural ventilation flow coefficient. Building energy saving, 2012(6): 81-84.

[3] D. Luo, G.L. Li. The design elements of integrated photovoltaic building. New material industry, 2011(8): 34-38.

[4] B.B. Gong, H.B. Gao, J. Qian. The influence of Greenhouse side window opening forms on flow coefficient value. Anhui agricultural science, 2011(2): 78-81.

[5] Luo M., Q. Shuai, R. Huang, S.P. Jiang. Research on the hollow glass packaging technology of gathering light photovoltaic component. Energy saving, 2011(6): 24-28.

[6] S.Y. He, Y.J. Chu, S.S. Li, Y.J. Cai. The solar photovoltaic glass curtain wall technology research and its application practice taking Changsha building as an example. Journal of architecture, 2012 (2): 78-79.

[7] H. Liu, Z.W. Lu, R. Zhu, H.X. Zhang. The development and tendency of gathering light photovoltaic system. Chinese optics and applied optics, 2012(1): 104-106.

[8] X.Y. Huang, Q. He, S.T. Xie. Design of integrated photovoltaic building. Chinese and foreign architecture, 2012(4): 136-137.

[9] R.C. Jin, J.Y. Qin, T. Gao, Wang. Application of the node disjoint multipath routing protocol of wireless multimedia sensor networks. Journal of sensor technology, 2010(7): 127-128.

[10] X.L. Fang, S.F. Shi, J.Z. Li. Research on wireless sensor network disjoint path routing algorithm. Computer research and development, 2011(2): 78-80.

[11] H. Wen, C. Lin, F.Y. Ren. The QoS architecture of wireless sensor network. Journal of computer, 2012(2): 45-46.

[12] Q. Lu, L.B. Du, Z. Zuo. The review of wireless multimedia sensor network node energy consumption problem. Sensor and micro system, 2011(2): 98-99.

[13] Y. Sun, H.D. Ma. Wireless multimedia sensor network QoS security. Chinese Journal of Electronics, 2011(6): 23-26.

[14] W.S. Luo, Y.P. Zhai, Q. Lu. Research on wireless multimedia sensor network. Journal of electronics and information technology, 2012(6): 34-37.

[15] S.N. Li, W.X. Teng, Q. Zhang. Research progress of wireless sensor network QoS routing. Application research of computers, 2012(4): 45-48.

[16] Li S.S., X.K. Liao, P.D. Zhu, S.L. Peng. A congestion aware multi path traffic assignment algorithm in wireless sensor network. Computer engineering and science, 2011(2): 49-50.

[17] H. Wang, N.H. Yu, Z.K. Liu. A new video transmission multi path packet scheduling algorithm in wireless Ad hoc network. Journal of electronics and information technology, 2013(4): 41-42.

[18] J.Z. Li, H. Gao. Research and development progress of wireless sensor networks. Computer research and development, 2013(1): 91-95. 